\title{
Long-term use of doxycycline can improve chronic asthma and possibly remodeling: the result of a pilot observation
}

This article was published in the following Dove Press journal:

Journal of Asthma and Allergy

7 August 2012

Number of times this article has been viewed

\section{Parthasarathi Bhattacharyya \\ Rantu Paul \\ Partha Bhattacharjee \\ Arko Ghosh \\ Ratna Dey \\ Malabika Ghosh \\ Madan Sharma}

Institute of Pulmocare and Research, CB 16, Salt Lake, Sector I,

Kolkata, India
Correspondence: Parthasarathi Bhattacharyya

Institute of Pulmocare and Research,

CB 16, Salt Lake, Sector I,

Kolkata-700064, India

Fax +9l 3323580424

Email parthachest@yahoo.com

\begin{abstract}
Progressive loss of lung function and reversibility characterize chronic asthma. The conventional therapy is targeted to control the disease without targeting the loss of lung function or reversibility. In a prospective real-world observation of long-term use of add-on doxycycline as a matrix-metalloproteinase inhibitor, we documented significant improvement in lung function with possible reversal of remodeling.
\end{abstract}

Background: Chronic asthma shows progressive decline in lung function with reduction or even loss of reversibility secondary to remodeling. A set of endopeptidase enzymes known as matrix metalloproteinases are intimately related to the pathogenesis of asthma and remodeling. The inhibition of matrix metalloproteinases is recognized as a prospective way of treating asthma and its corresponding structural remodeling.

Methods: In a randomized, prospective, real-world study, we have observed the change in lung function (spirometry) with an add-on of long-term doxycycline to standard asthma therapy as per the Global Initiative for Asthma guidelines in a small asthmatic population. The change in terms of forced expiratory volume $\left(\mathrm{FEV}_{1}\right)$, forced vital capacity $(\mathrm{FVC})$, percent of $\mathrm{FEV}_{1}$ $\left(\mathrm{FEV}_{1} \%\right)$, and forced expiratory flow $\left(\mathrm{FEF}_{25-75}\right)$ were noted following variable duration of doxycycline therapy.

Results: There has been a global improvement in all the parameters in all the six patients suggesting improvement in obstruction, and reduction in air trapping following a treatment of add-on doxycycline for a mean duration of $162.83 \pm 83.07$ days. Of the changes seen, the post bronchodilator $\mathrm{FEV}_{1}$, the $\mathrm{FVC}$, and the $\mathrm{FEF}_{25-75}$ showed significant improvements with the $P$-value set at $0.004,0.054$, and 0.031 , respectively. There was also evidence of the reversal of remodeling from the improvement in the $\mathrm{FEV}_{1} / \mathrm{FVC}$ ratio. Moreover there was a greater than expected improvement of pre-bronchodilator $\mathrm{FEV}_{1}$ after treatment that far surpassed the initial post-bronchodialator $\mathrm{FEV}_{1}$ value. Even after such a change, there were presences of some reversibility suggesting room for further improvement.

Conclusion: The results suggest significant improvements in the obstructive parameters used to evaluate asthma, with possible reversal of remodeling evident in chronic asthmatics when treated with doxycycline in addition to standard therapies. This observation needs further scientific validation.

Keywords: chronic asthma, doxycycline, $\mathrm{FEV}_{1}, \mathrm{FEV}_{1} / \mathrm{FVC}$, matrix metalliproteinase

\section{Introduction}

Asthma is a disease of airway inflammation and airway hyper-responsiveness ${ }^{1}$ with progressive narrowing of the airways due to both reversible and irreversible functional and structural changes; the apparently irreversible changes in chronic asthma have been denoted as remodeling given that they result in reduction in lung function 
and vary in terms of the degree of reversibility. ${ }^{2}$ Assessment of airways by high-resolution computerized tomography (CT) of the chest can have a good correlation to the pathological measures of remodeling. ${ }^{3}$ Of late, the forced expiratory volume $\left(\mathrm{FEV}_{1}\right)$ forced vital capacity $(\mathrm{FVC})$ ratio $\left(\mathrm{FEV}_{1} / \mathrm{FVC}\right)$ has also been detected as a surrogate marker of remodeling that correlates well with the airway changes assessed by CT scan. ${ }^{4}$ The pathophysiology of asthma inflammation and airway remodeling has been marked by different microstructural changes including abnormal extracellular matrix turnover and fibrosis ${ }^{5,6}$ through the participation of an enzyme system called matrix metalloproteinase (MMPs) and its tissue inhibitor. ${ }^{7-9}$ Since modulation of the process by inhibition of MMPs may be beneficial to the asthmatics, we used doxycycline on a long-term basis in an open, prospective, real-world observation. We conducted this pilot work to see the effect of this antibiotic for its additional property of matrix metalloproteinase inhibition ${ }^{10-12}$ and suppression of immunoglobulin-E (IgE) ${ }^{13}$ alongside the use of standard asthma medications.

\section{Methods}

\section{Inclusion of patients}

We selected chronic asthmatics from the outpatient department of the institute who had long standing history of asthma symptoms with documented airflow limitation and significant reversibility (200 $\mathrm{mL}$ and $12 \%)$ using spirometry in compliance with the American Thoracic Society guideline. ${ }^{14}$ The subjects were incorporated in a real-world observation protocol (approved by the Institutional Ethics Committee) upon signing the written informed consent form to undergo treatment with doxycycline on a long-term basis. Patients younger than 13 years and older than 75 years of age, those unwilling to undergo the study, and those having previous history of doxycycline intolerance or history of exacerbation within the preceding 6 weeks were excluded. Since it was a real world observation, we kept the study in tandem with the practicing style of the physician and the logistics of the real world. All the patients were informed of the need to (a) have repeated spirometry examinations; (b) attend regular follow-up visits; and (c) report the side effects (experienced or suspected), if any, apart from the need to continue doxycycline as an add-on therapy on top of optimal asthma treatments as per the Global Initiative for Asthma guidelines. ${ }^{15}$ All the patients were on inhaled longacting beta agonists plus inhaled corticosteroids with inhaled reliever short-acting $\beta_{2}$ agonist prior to randomization so as to stabilize symptoms for at least 6 weeks. Patients were informed about the possible side effects of doxycycline and were instructed to consume the medicine at least 1 hour after eating. The offered dose of doxycycline was $100 \mathrm{mg}$ twice daily and $100 \mathrm{mg}$ once daily for patients with body weight over $40 \mathrm{~kg}$ or less than $40 \mathrm{~kg}$, respectively. Ranitidine was co-prescribed universally to lessen the chance of gastrointestinal intolerance. The baseline spirometry data were preserved and the follow up spirometry data were incorporated for statistical analysis as soon as they were available. We looked for changes in both the pre- (initial) and post-bronchodilator values of spirometric variables across the $\mathrm{FEV}_{1}, \mathrm{FVC}_{\text {, ratio of }} \mathrm{FEV}_{1} / \mathrm{FVC}$, and $\mathrm{FEF}_{25-75}$ for documentation of improvement, and changes in the $\mathrm{FEV}_{1} / \mathrm{FVC}$ for marking the improvement of remodeling according to the observations outlined by Chae et al. ${ }^{4}$

Statistical calculations were done on these spirometric variables using two-tailed paired $t$-tests, and significance was noted with a $P$-value $<0.05$.

\section{Results}

Of the 24 patients being prescribed add-on doxycycline, a total of six patients (three males and three females, mean age of $47.0 \pm 14.6$ years) were included for data analysis. Their follow-ups were noted during the period from March 15, 2011 to November 03, 2011. Each patient showed an improvement in their asthma symptoms and exhibited reversibility, according to spirometry results. From the rest of the 18 patients, 10 did not perform repeat spirometry before or during the period of data collection. A total of four patients consumed the medicine inconsistently, two had stopped the therapy after a few days, and one had started the drug only recently. In another patient, the drug was stopped for subsequent diagnosis of tuberculosis.

The mean duration of add-on doxycycline between the baseline and posttreatment spirometric assessment was noted as $162.83 \pm 83.07$ days and the changes in the spirometric variables are displayed in Table 1. There was a global improvement across all the parameters; however, the change in the post-bronchodilator $\mathrm{FEV}_{1}$ was the most significant $(P=0.004)$. The other significant changes noted were post-bronchodilator FVC $(P=0.054)$, and both preand post-bronchodilator $\mathrm{FEF}_{25-75}(P=0.023$ and $P=0.031$, respectively).

When the pre- (baseline) and posttreatment values were plotted on a duration scale, all the variables showed progressive improvement with time. However, the postbronchodilator values exhibited more significant improvements compared to the pre-bronchodilator values for $\mathrm{FEV}_{1}$, 
Table I Changes in spirometric variables in response to treatment of add-on doxycycline

\begin{tabular}{|c|c|c|c|c|c|c|}
\hline & $\begin{array}{l}\text { Before treatment } \\
\text { pre-BD }\end{array}$ & $\begin{array}{l}\text { After treatment } \\
\text { pre-BD }\end{array}$ & $P$-value & $\begin{array}{l}\text { Before treatment } \\
\text { post-BD }\end{array}$ & $\begin{array}{l}\text { After treatment } \\
\text { post-BD }\end{array}$ & $P$-value \\
\hline & Mean \pm SD & Mean \pm SD & & Mean \pm SD & Mean \pm SD & \\
\hline $\mathrm{FEV}_{1}(\mathrm{~L})$ & $1.12 \pm 0.40$ & $1.38 \pm 0.29$ & 0.14 & $1.30 \pm 0.43$ & $1.61 \pm 0.34$ & 0.004 \\
\hline FVC (L) & $1.97 \pm 0.60$ & $2.13 \pm 0.49$ & 0.256 & $2.12 \pm 0.63$ & $2.44 \pm 0.56$ & 0.054 \\
\hline $\mathrm{FEV}_{1} \%$ & $56.98 \pm 11.73$ & $65.13 \pm 6.61$ & 0.028 & $61.83 \pm 13.33$ & $66.55 \pm 6.84$ & 0.227 \\
\hline $\mathrm{FEF}_{25-75}(\mathrm{~L} / \mathrm{s})$ & $0.68 \pm 0.29$ & $0.90 \pm 0.21$ & 0.023 & $0.86 \pm 0.31$ & $1.06 \pm 0.23$ & 0.031 \\
\hline
\end{tabular}

Notes: The table shows the change in the different spirometric variables $\left(\mathrm{FEV}_{1}, \mathrm{FVC}, \mathrm{FEV}_{1} \%\right.$, and $\mathrm{FEF}_{25-75}$ ), in terms of both pre- and post-bronchodilator values from treatment of add-on doxycycline. The significant changes $(P>0.05)$ are marked in bold.

Abbreviations: $\mathrm{BD}$, bronchodilator; $P$, probability level; SD, standard deviation; $\mathrm{FEV}_{1}$, forced expiratory volume; L, liters; FVC, forced vital capacity; FEV $\%$, percentage of forced expiratory flow; $\mathrm{FEF}_{25-75}(\mathrm{~L} / \mathrm{s})$, patient's exhaled volume (liters per second).

$\mathrm{FVC}$, percentage of forced exhaled volume $\left(\mathrm{FEV}_{1} \%\right)$, and $\mathrm{FEF}_{25-75}$ (displayed in Figure 1A to D). No adverse effects of doxycycline were reported by the patients.

\section{Discussion}

Asthma is a global problem with a huge health care burden, ${ }^{16}$ and remodeling of asthma is a universal phenomenon. The loss of lung function has been found to be accelerated in asthma despite therapy. ${ }^{17,18}$ So far, the treatment of asthma consists essentially of inhaled bronchodilators and inhaled corticosteroids with oral bronchodilators and anti-inflammatory
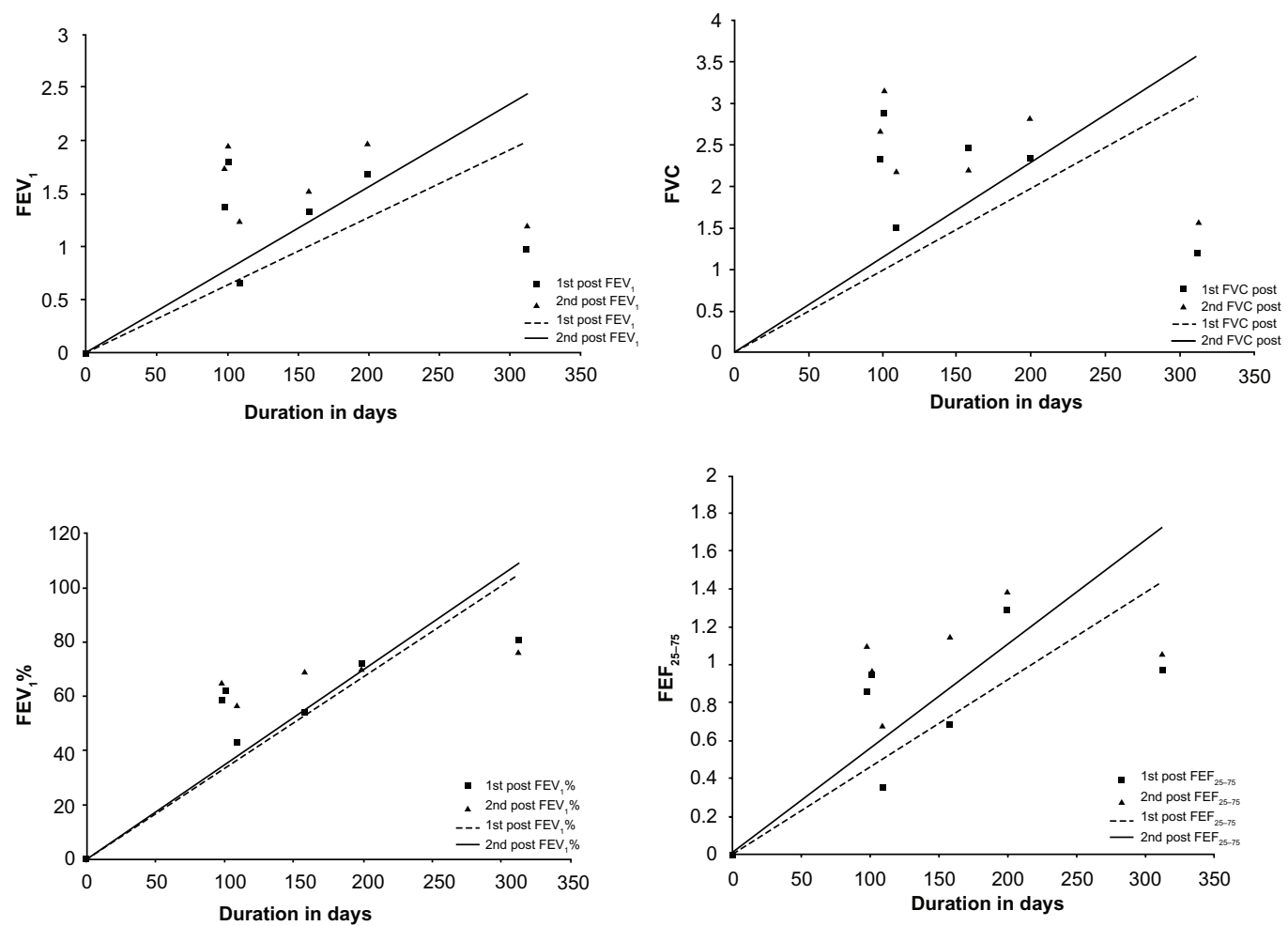

Figure I Changes in $\mathrm{FEV}_{1}, \mathrm{FVC}, \mathrm{FEV}_{1} \%$, and $\mathrm{FEF}_{25-75}$ as a function of initial and after use of add-on doxycycline treatment. (A-D) denote the changes in different parameters $\left(\mathrm{FEV}_{1}, \mathrm{FVC}, \mathrm{FEV}_{1} \%, \mathrm{FEF}_{25-75}\right.$, respectively), expressed as a function of time in both their initial (dotted line) and after use of add-on doxycycline treatment (continuous line) values.

Abbreviations: $\mathrm{FEV}_{1}$, forced expiratory volume; L, liters; FVC, forced vital capacity; FEV,\%, percentage of forced expiratory volume; FEF $25-75$ (L/s), patient's exhaled flow (liters per second). 
Matrix metalloproteinases, a class of Zn-endopeptidase, and their tissue inhibitors (TIMPs) play a very significant role in the process. Several MMPS are found up-regulated in asthma; of these, MMP-9 has been found in higher quantities in the sputum, bronchoalveolar lavage fluid, and serum of asthmatics, ${ }^{7-9}$ and is also found to be elevated in several different situations such as asthma exacerbation, ${ }^{21}$ occupational asthma, ${ }^{22}$ and nocturnal asthma. ${ }^{23}$ Similarly, the tissue inhibitor of matrix metalloproteinase-1 (TIMP-1) has been found to be elevated in asthmatics. ${ }^{7}$ The MMP/ TIMP balance is regarded as important in the development of allergy-induced asthma since it is reduced by the pulmonary administration of TIMP-1 or TIMP-2. ${ }^{24}$ In animal models, different MMP inhibitors are found to reduce airway inflammation ${ }^{24}$ and bronchial hyperreactivity. ${ }^{25}$

Both early and late reactions in asthma have been found to be reduced in sheep models when MMP inhibitors are used, and thus MMP inhibition may be a prospective therapeutic target in asthmatics. ${ }^{26,27}$ We have tried to exploit this concept in a few cases of chronic asthma with the long-term use of a known MMP inhibitor, doxycycline. ${ }^{10,11,12}$ Such use of doxycycline has been approved by the United States Food and Drug Administration for the treatment of periodontal disease, ${ }^{28}$ and the long-term use of doxycycline has been documented in several other indications with few toxicities noted. ${ }^{29-32}$

Incidentally, doxycycline is also able to suppress $\operatorname{IgE}$, and this property can also be exploited for the treatment of asthma. ${ }^{13}$ Daoud et al have documented the use of minocycline among people with asthma, and they examined the effects of this drug across a number of spirometric parameters of lung function as related to IgE suppression. ${ }^{33,34}$ Doxycycline was found to successfully reduce the airway inflammation and hyper-responsiveness in murine model of Toluene di-isocyanate induced asthma. ${ }^{35}$ Thus, we conclude that doxycycline, by virtue of its MMP inhibitory and $\operatorname{IgE}$ suppressive properties, can be a useful adjunct in the management of asthma.

In our observations, we noted significant improvements across measures of obstruction $\left(\mathrm{FEV}_{1}\right)$, and also across the surrogate marker of remodeling $\mathrm{FEV}_{1} / \mathrm{FVC}^{3}$ The changes in $\mathrm{FEF}_{25-75}$ and $\mathrm{FEV}_{1}$ suggest that the observed changes took place both in medium and small-sized airways. Given that the improvement exceeded the expected post-bronchodilator value and yet maintaining some reversibility, it suggests some structural changes that may have resulted from the use of the intervention to the benefit of the patients. Such supranormal improvement in the posttreatment spirometry with demonstration of existence of some reversibility suggests the scope of further improvement. Our results clearly exceeded our expectations, and this implies that the so-called remodeling is not necessarily a fixed structural change.

Our observation may be the first of its kind to show a change in the natural history of asthma by pharmacotherapy. Subsequent research should try to address how long this therapy can be continued and how far the natural history of asthma can be changed. It is not possible to speak about the side effects of doxycycline in this observation given that our sample size included a small number of patients. In addition, the chances of gastrointestinal toxicities and the reflux related to the administration of this drug were, perhaps, lessened by the universal use of ranitidine. A good prospective, randomized, double blind study with a much larger sample population might be able to address these questions.

Despite several weaknesses in the current study (ie, small sample size, real-world observation, no control group, no histological proof, and no high-resolution CT assessment of remodeling), our observations warrant attention and further validation.

\section{Disclosure}

The authors report no conflicts of interest in this work.

\section{References}

1. Standards for the diagnosis and care of patients with chronic obstructive pulmonary disease (COPD) and asthma. This official statement of the American Thoracic Society was adopted by the ATS Board of Directors, November 1986. Am Rev Respir Dis. 1987;136: 225-244.

2. Elias JA, Zhu Z, Chupp G, Homer RJ. Airway remodeling in asthma. J Clin Invest. 1999;104(8):1001-1006.

3. Aysola RS, Hoffman EA, Gierada D, et al. Airway remodeling measured by multidetector CT is increased in severe asthma and correlates with pathology. Chest. 2008;134(6):1183-1191.

4. Chae EJ, Kim TB, Cho YS, et al. Airway measurement for airway remodeling defined by post-bronchodilator FEV1/FVC in asthma: investigation using inspiration-expiration computed tomography. Allergy Asthma Immunol Res. 2011;3(2):111-117.

5. Mauad T, Xavier AC, Saldiva PH, Dolhnikoff M. Elastosis and fragmentation of fibers of the elastic system in fatal asthma. Am J Respir Crit Care Med. 1999;160(3):968-975.

6. Parameswaran K, Willems-Widyastuti A, Alagappan VK, Radford K, Kranenburg AR, Sharma HS. Role of extracellular matrix and its regulators in human airway smooth muscle biology. Cell Biochem Biophys. 2006;449(1):139-146.

7. Cataldo D, Munaut C, Noel A, et al. MMP-2- and MMP-9-linked gelatinolytic activity in the sputum from patients with asthma and chronic obstructive pulmonary disease. Int Arch Allergy Immunol. 2000;123(3):259-267.

8. Mautino G, Henriquet C, Gougat C, et al. Increased expression of tissue inhibitor of metalloproteinase-1 and loss of correlation with matrix metalloproteinase-9 by macrophages in asthma. Lab Invest. 1999; 79(1):39-47. 
9. VignolaAM, Riccobono L, MirabellaA, et al. Sputum metalloproteinase-9/ tissue inhibitor of metalloproteinase-1 ratio correlates with airflow obstruction in asthma and chronic bronchitis. Am J Respir Crit Care Med. 1998;158(6):1945-1950.

10. Pires PW, Rogers CT, McClain JL, Garver HS, Fink GD, Dorrance AM. Doxycycline, a matrix metalloprotease inhibitor, reduces vascular remodeling and damage after cerebral ischemia in stroke-prone spontaneously hypertensive rats. Am J Physiol Heart Circ Physiol. 2011;301(1):H87-H97.

11. Ren S, Guo LL, Yang J, et al. Doxycycline attenuates acrolein-induced mucin production, in part by inhibiting MMP-9. Eur J Pharmacol. 2011;650(1):418-423.

12. Kaito K, Urayama H, Watanabe G. Doxycycline treatment in a model of early abdominal aortic aneurysm. Surg Today. 2003;33(6):426-443.

13. Smith-Norowitz TA, Bluth $\mathrm{MH}$, Drew H, et al. Effect of minocycline and doxycycline on IgE responses. Ann Allergy Asthma Immunol. 2002;89(2):172-179

14. Pellegrino R, Viegi G, Brusasco V, Crapo RO, et al. Interpretive strategies for lung function tests. Eur Respir J. 2005;26(5):948-968.

15. http://www.ginasthma.org. [homepage on the Internet]. Pocket guide for asthma management and prevention. Global Initiative for Asthma (GINA); updated 2011. Available from: http://www.ginasthma.org/guidelinespocket-guide-for-asthma-management.html. Accessed 18 June, 2012.

16. Masoli M, Fabian D, Holt S, Beasley R; for Global Initiative for Asthma (GINA) Program. The global burden of asthma: executive summary of the GINA Dissemination Committee report. Allergy. 2004;59(5):469-478.

17. Peat JK, Woolcock AJ, Cullen K. Rate of decline of lung function in subjects with asthma. Eur J Respir Dis. 1987;70(3):171-179.

18. Lange P, Parner J, Vestbo J, Schnohr P, Jensen G. A 15-year follow-up study of ventilatory function in adults with asthma. $N$ Engl J Med. 1998;339(17):1194-1200.

19. Chakir J, Shannon J, Molet S, et al. Airway remodeling associated mediators in moderate to severe asthma: effect of steroids on TGF-beta, IL-11, IL-17, and type I and type III collagen expression. J Allergy Clin Immunol. 2003;111(6):1293-1298.

20. de Medeiros Matsushita M, da Silva LF, dos Santos MA, et al. Airway proteoglycans are differentially altered in fatal asthma. J Pathol. 2005;207(1):102-110.

21. Lee YC, Lee HB, Rhee YK, Song CH. The involvement of matrix metalloproteinase-9 in airway inflammation of patients with acute asthma. Clin Exp Allergy. 2001;31(10):1623-1630.

22. Palikhe NS, Kim JH, Park HS. Biomarkers predicting isocyanateinduced asthma. Allergy Asthma Immunol Res. 2011;3(1):21-26.
23. Pham DN, Chu HW, Martin RJ, Kraft M. Increased matrix metalloproteinase-9 with elastolysis in nocturnal asthma. Ann Allergy Asthma Immunol. 2003;90(1):72-78.

24. Kumagai K, Ohno I, Okada S, et al. Inhibition of matrix metalloproteinases prevents allergen-induced airway inflammation in a murine model of asthma. J Immunol. 1999;162(7):4212-4219.

25. Bruce C, Thomas PS. The effect of marimastat, a metalloprotease inhibitor, on allergen-induced asthmatic hyper-reactivity. Toxicol Appl Pharmacol. 2005;205(2):126-132.

26. Mukhopadhyay S, Sypek J, Tavendale R, et al. Matrix metalloproteinase12 is a therapeutic target for asthma in children and young adults. J Allergy Clin Immunol. 2010;126(1):70-76.

27. $\mathrm{Li} \mathrm{W}, \mathrm{Li} \mathrm{J}, \mathrm{Wu} \mathrm{Y}$, et al. Identification of an orally efficacious matrix metalloprotease 12 inhibitor for potential treatment of asthma. $J$ Med Chem. 2009;52(17):5408-5419.

28. Golub LM, Lee HM, Ryan ME, Giannobile WV, Payne J, Sorsa T. Tetracyclines inhibit connective tissue breakdown by multiple nonantimicrobial mechanisms. Adv Dent Res. 1998;12(2):12-26.

29. Bhattacharyya P, Nag S, Acharyya Ghosh D, Chowdhury SR, Bardhan S, Mukherjee A. Treatment of probable idiopathic pulmonary fibrosis with long term doxycycline, a matrix metalloproteinase inhibitor. Indian Journal of Chest Disease and Allied Sciences. 2007;49(3):180.

30. Bhattacharyya P, Nag S, Bardhan S, et al. The role of long-term doxycycline in patients of idiopathic pulmonaryfibrosis: The results of an open prospective trial. Lung India. 2009;26(3):81-85.

31. Newton PN, Chaulet JF, Brockman A, et al. Pharmacokinetics of oral doxycycline during combination treatment of severe falciparum malaria. Antimicrob Agents Chemother. 2005;49(4):1622-1625.

32. http://www.hpa.org.uk. [homepage on the Internet]. Malaria. London: Health Protection Agency; 2012. Available from: http://www.hpa.org uk/infections/topics_az/malaria/. Accessed 18 June, 2012.

33. Daoud A, Gloria CJ, Taningco G, et al. Minocycline treatment results in reduced oral steroid requirements in adult asthma. Allergy Asthma Proc. 2008;29(3):286-294.

34. Joks R, Smith-Norowitz T, Nowakowski M, Bluth MH, Durkin HG. Tetracycline-mediated IgE isotype-specific suppression of ongoing human and murine $\mathrm{IgE}$ responses in vivo and murine memory $\operatorname{IgE}$ responses induced in vitro. Int Immunol. 2010;22(4):281-288.

35. Lee KS, Jin SM, Kim SS, Lee YC. Doxycycline reduces airway inflammation and hyperresponsiveness in a murine model of toluene diisocyanate-induced asthma. J Allergy Clin Immunol. 2004;113(5): 902-909.
Journal of Asthma and Allergy

\section{Publish your work in this journal}

The Journal of Asthma and Allergy is an international, peer-reviewed open-access journal publishing original research, reports, editorials and commentaries on the following topics: Asthma; Pulmonary physiology; Asthma related clinical health; Clinical immunology and the immunological basis of disease; Pharmacological interventions and

\section{Dovepress}

new therapies. Issues of patient safety and quality of care will also be considered. The manuscript management system is completely online and includes a very quick and fair peer-review system, which is all easy to use. Visit http://www.dovepress.com/testimonials.php to read real quotes from published authors. 